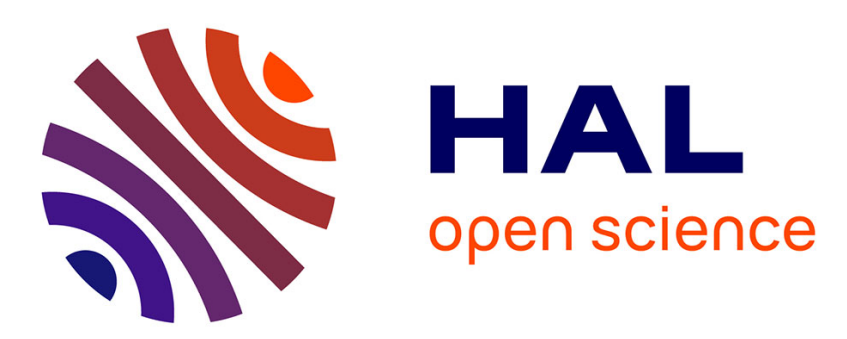

\title{
Incommensurate Intermodulation of an Organic Intergrowth Compound Observed by Neutron Scattering
}

R. Lefort, J. Etrillard, B. Toudic, F. Guillaume, T. Breczewski, P. Bourges

\section{To cite this version:}

R. Lefort, J. Etrillard, B. Toudic, F. Guillaume, T. Breczewski, et al.. Incommensurate Intermodulation of an Organic Intergrowth Compound Observed by Neutron Scattering. Physical Review Letters, 1996, 77 (19), pp.4027-4030. 10.1103/PhysRevLett.77.4027 . hal-01009275

\section{HAL Id: hal-01009275 \\ https://hal.science/hal-01009275}

Submitted on 17 Jun 2014

HAL is a multi-disciplinary open access archive for the deposit and dissemination of scientific research documents, whether they are published or not. The documents may come from teaching and research institutions in France or abroad, or from public or private research centers.
L'archive ouverte pluridisciplinaire HAL, est destinée au dépôt et à la diffusion de documents scientifiques de niveau recherche, publiés ou non, émanant des établissements d'enseignement et de recherche français ou étrangers, des laboratoires publics ou privés. 


\title{
Incommensurate Intermodulation of an Organic Intergrowth Compound Observed by Neutron Scattering
}

\author{
R. Lefort, ${ }^{1}$ J. Etrillard, ${ }^{1}$ B. Toudic, ${ }^{1}$ F. Guillaume,${ }^{2}$ T. Breczewski, ${ }^{3}$ and P. Bourges ${ }^{4}$ \\ ${ }^{1}$ Groupe Matière Condensée et Matériaux, URA au CNRS 804, Université de Rennes I, 35042 Rennes, France \\ ${ }^{2}$ Laboratoire de Spectroscopie Moléculaire et Cristalline, URA au CNRS 124, Université de Bordeaux I, 33405 Talence, France \\ ${ }^{3}$ Facultad de Ciencias, Universidad del Pais Vasco, Apdo 644, Bilbao, Spain \\ ${ }^{4}$ Laboratoire Léon Brillouin, CEA-CNRS, CE-Saclay, 91191 Gif-sur-Yvette, France
}

(Received 26 July 1996)

\begin{abstract}
The observation of an incommensurate diffraction pattern in urea inclusion compounds by neutron diffraction is reported. It reveals for the first time in these compounds the existence of all kinds of reflections expected for an intermodulated composite. The superspace analysis together with the temperature evolution of some characteristic reflections are presented. [S0031-9007(96)01585-2]
\end{abstract}

PACS numbers: 61.50.-f, 61.12.Ex, 64.70.Rh

During the past years, quasiperiodic structures, such as incommensurately modulated crystals, incommensurate composites, and quasicrystals, have raised a great deal of interest, profoundly modifying the views about the very basic concepts of crystallography (for a review see Ref. [1]). Incommensurate composite structures actually appear somehow intermediate in complexity in these quasiperiodic systems, since they consist of two or more interpenetrating sublattices with mutually incommensurate periodicities in at least one direction $[2,3]$. Thus there is no basic periodic lattice, but, by neglecting the modulation between different subsystems, the diffraction pattern is the sum of the individual one of each average sublattice. When, however, the subsystems interact, distortions with the periodicity of the neighboring sublattices are introduced in each of the lattices. Microscopic models have been developed to describe the effects of such competing periodicities and to take into account the discreteness of the lattice $[4,5]$. Urea inclusion compounds constitute a very interesting family of molecular composite structures, where long chain hydrocarbons or substituted hydrocarbon molecules are included in channels within the framework of urea molecules [6-14]. A very rich diffraction pattern is then observed, but in practice, up to now, no reflections with significant intensity were observed in satellite positions for incommensurate urea inclusion compounds [9]. In this Letter, we present for the first time a direct observation of the associated additional reflections of such molecular composites, analyzed in the frame of superspace group description. Such an observation was made possible by using neutron diffraction with a large single crystal of $n$-nonadecane/urea inclusion compound.

Urea inclusion compounds with $n$-alkanes, $\mathrm{OC}\left(\mathrm{NH}_{2}\right)_{2}+\mathrm{C}_{n} \mathrm{H}_{2 n+2}$, consist of a three-dimensionally connected network of urea molecules (host sublattice). At room temperature, the urea structure, as determined by $x$-ray diffraction, is described by the hexagonal space group $P 6_{1} 22$ [11]. Honeycomblike infinite channels parallel to the screw axis $\mathbf{c}$ accommodate alkane molecules (guest subsystem). The structural periodicities of the urea $\left(c_{\text {host }}\right)$ and the alkane $\left(c_{\text {guest }}\right)$ along the channel axis are incommensurate, and the misfit parameter is defined by the ratio of two lattice constants $\alpha=c_{\text {host }} / c_{\text {guest }}$ and is constant at all temperatures. On lowering the temperature, these inclusion compounds exhibit a structural change toward an orthorhombic space group $P 2{ }_{1} 2_{1} 2_{1}$ [12] at a temperature that depends on the length of the $n$-alkane chains.

In this paper, we discuss the neutron diffraction data obtained on $n$-nonadecane/urea. For this compound, the expected value for $\alpha=0.418$, and the phase transition occurs around $160 \mathrm{~K}$.

The neutron scattering experiments were performed at the Laboratoire Léon Brillouin at the Orphee reactor (Saclay). Most of the data were collected on the tripleaxis spectrometer G43 installed on a cold neutron guide. The incident wave vector used was $k_{i}=2.662 \AA^{-1}$ with a graphite filter in order to avoid $\lambda / 2$ contamination in the incident beam. A sas-displex system provided a temperature stability better than $0.1 \mathrm{~K}$ from 15 to $280 \mathrm{~K}$. The sample was prepared by slow evaporation of mixed solutions of urea- $h_{4}$ and $n$-nonadecane in ethanol and isopropanol. The volume of the resultant single crystal is $(4 \times 5 \times 15) \mathrm{mm}^{3}$, and its measured mosaic spread is found to be better than $22^{\prime}$ from neutron analysis. The retained scattering plane was $\left(\mathbf{a}^{*}, \mathbf{c}^{*}\right)$. Below the transition temperature, breaking of symmetry generates six twinned orthorhombic domains [6]. This causes the splitting of the measured reflections within the $\left(\mathbf{a}^{*}, \mathbf{b}^{*}\right)$ plane, but does not affect their location along the $\mathbf{c}^{*}$ axis, allowing the hexagonal indexing to be kept at all temperatures. The mean $\mathbf{a}^{*}$ axis reference was chosen on the position in reciprocal space where the respective (110) and (110) reflections (orthorhombic notation) of two domains are superimposed.

Figures 1 and 2 show scans recorded for different values of the Miller index $h$ along the $\mathbf{c}^{*}$ direction, where indexation refers to the urea reciprocal parameter. In Fig. 1, for 


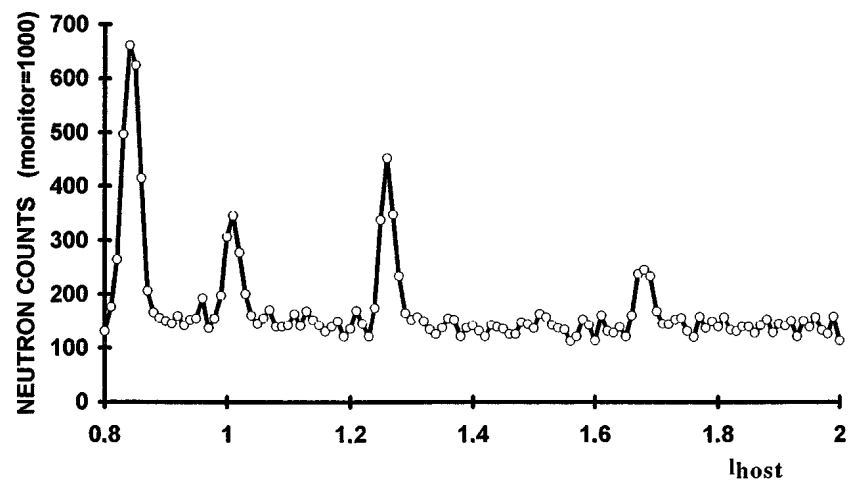

FIG. 1. Neutron diffraction scans $\left(00 l_{\text {host }}\right)$ measured at $18 \mathrm{~K}$ on a single crystal of $\mathrm{C}_{19} \mathrm{H}_{40}$ /urea inclusion compound. Indexation along $l_{\text {host }}$ refers to the urea $\mathbf{c}^{*}$ reciprocal parameter.

$h=0$ Bragg reflections appear at positions multiple of the misfit parameter $\alpha$. The weak nonzero value observed for $1_{\text {host }}=1$ is certainly due to multiple diffraction. Figure 2 , for $h \neq 0$, reveals the same type of reflections (integer $1_{\text {host }}$ and $1_{\text {host }}=n \alpha$ ), and between them additional reflections appear at positions incommensurate with both the host and guest periodicities along the channel direction.

This diffraction pattern has to be analyzed in the frame of an intermodulated incommensurate composite structure. In that case, the whole crystal can be described as the union of two incommensurate modulated lattices, and one can expect the diffraction pattern to no longer be the simple superimposition of two uncorrelated ones, but to reveal new intensity relations and additional reflections. To define those effects of the intermodulation of alkane and urea, a superspace description of the inclusion compound can be applied [1]. Defining the urea host basic structure by $\mathbf{a}^{*}, \mathbf{b}^{*}, \mathbf{c}_{\text {host }}^{*}$ and the basic alkane guest structure by $\mathbf{a}^{*}, \mathbf{b}^{*}, \mathbf{c}_{\text {guest }}^{*}=\alpha \mathbf{c}_{\text {host }}^{*}, \mathrm{a}(3+1)$ dimensional space $\left\{\mathbf{a}^{*}, \mathbf{b}^{*}, \mathbf{c}_{\text {host }}^{*}, \mathbf{d}^{*}\right\}$ may be constructed, where the projection of $\mathbf{d}^{*}$ onto the $\mathbf{c}^{*}$ direction (physical space) is equal to $\alpha$. To each reciprocal vector $\mathbf{q}_{h k l m}=h \mathbf{a}^{*}+k \mathbf{b}^{*}+1 \mathbf{c}_{\text {host }}^{*}+m \mathbf{d}^{*}$ in superspace is associated a Bragg-type reflection in physical space. A possible representation (Fig. 3 ) of the $\left(\mathbf{c}_{\text {host }}^{*}, \mathbf{d}^{*}\right)$ section of the reciprocal superspace of $n$-nonadecane urea inclusion compound shows that each $\mathbf{q}_{h k l m}$ projects onto physical space to a satellite position $\mathbf{q}=1 \mathbf{c}_{\text {host }}^{*}+m \mathbf{c}_{\text {guest }}^{*}$. A total agreement between this indexation and the experimental location of the reflections is obtained, up to quite high satellite order (see Table I). The different components of the diffraction pattern can then be classified as follows: ( $h k 00)$ common reflections to urea host and alkane guest lattices, $(h k l 0)$ main reflections of host, $(h k 0 \mathrm{~m})$ main reflections of guest, and $(h \mathrm{kl} \mathrm{m})$ pure satellites due to intermodulation of host and guest.

A complete knowledge of the intermodulation functions, in the frame of a superspace structure factor calculation [1], should be necessary to discuss the intensities of

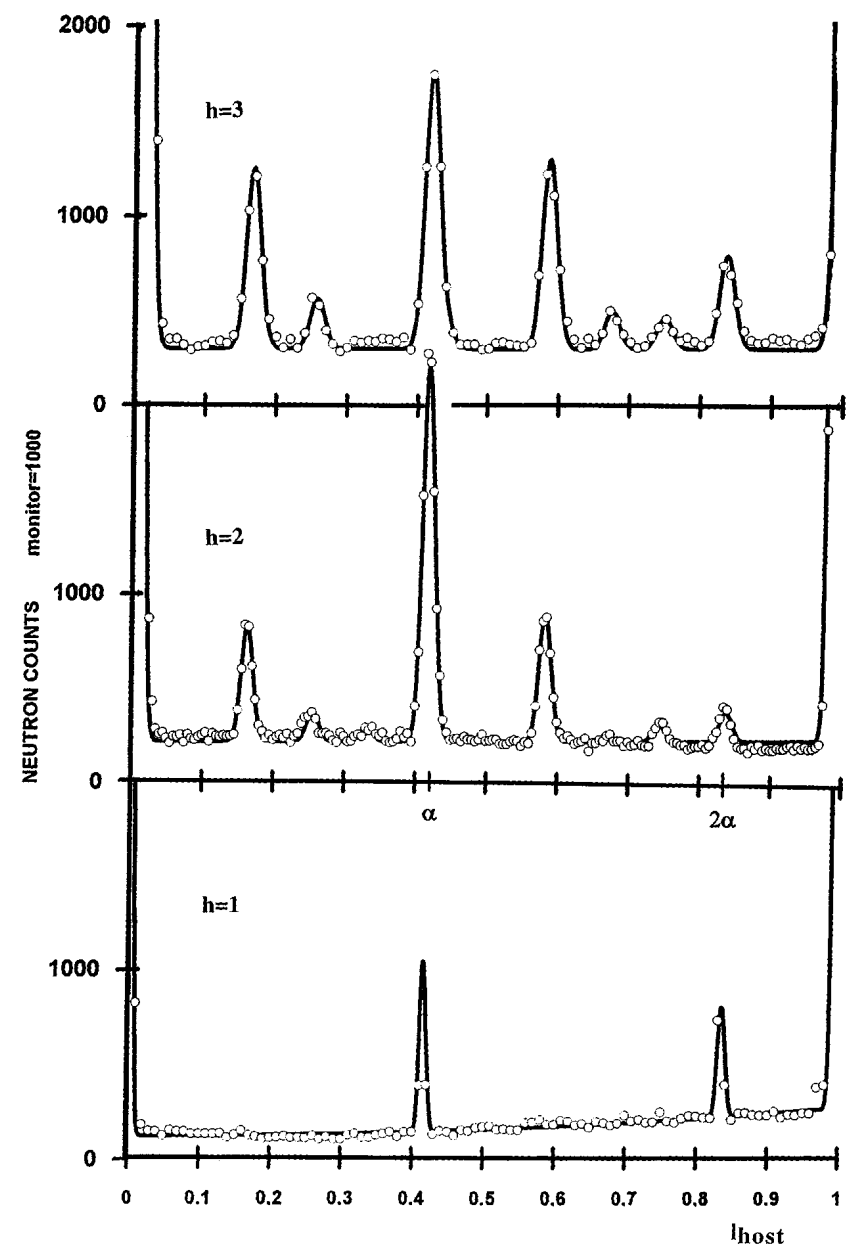

FIG. 2. Diffraction scans $\left(10 l_{\text {host }}\right),\left(20 l_{\text {host }}\right)$, and $\left(30 l_{\text {host }}\right)$ at $18 \mathrm{~K}$. All kinds of reflections expected for an intermodulated composite structure appear.

these reflections, as both sublattices contribute to each diffracted spot. The observation of pure satellites as Bragg peaks suggests that the intermodulation which the composite structure experiences is a three-dimensionally long range ordered phenomenon. To create such an effect, one could therefore expect the included alkane chains to be themselves, at least locally, three-dimensionally ordered. This does not seem to be in agreement with the existence of diffuse lines perpendicular to the $\mathbf{c}^{*}$ direction occurring on guest $n \alpha$ positions, indicating a rather one-dimensional ordering. These $(h k 0 \mathrm{~m})$ lines were reported by $\mathrm{x}$-ray diffraction as the $s$-diffuse scattering [6]. They are also observed by neutron measurements as a very weak diffracted intensity as narrow as a Bragg reflection in the $\mathbf{c}^{*}$ direction.

Another fundamental point concerns the temperature dependence of those different order satellites, indicating the evolution of the modulation and therefore the strength of the competing interactions. In the $\left(\mathbf{a}^{*}, \mathbf{c}^{*}\right)$ plane, the already mentioned twinning in the low temperature phase does not allow an easy direct measurement of intensities 

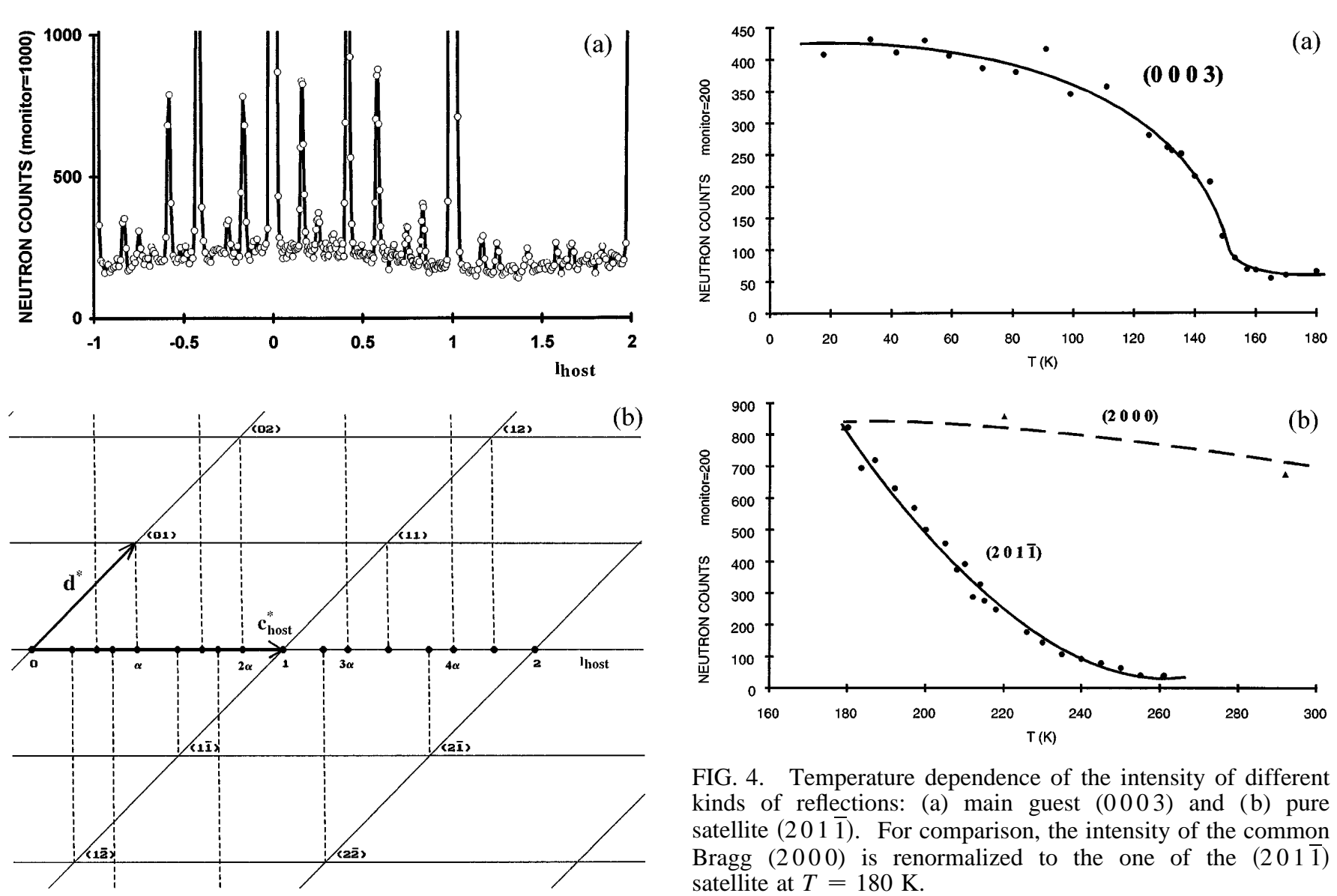

FIG. 4. Temperature dependence of the intensity of different kinds of reflections: (a) main guest (0003) and (b) pure satellite $(201 \overline{1})$. For comparison, the intensity of the common Bragg (2000) is renormalized to the one of the (2011) satellite at $T=180 \mathrm{~K}$.

FIG. 3. Neutron diffraction scan $\left(\begin{array}{lll}2 & 0 & l_{\text {host }}\end{array}\right)$ up to $l_{\text {host }}=2$ at $T=18 K(a)$, and its superspace indexation (b).

for $h \neq 0$. However, $(00 \mathrm{~lm})$ reflections are not affected by the existence of domains. Figure 4(a) shows the tem-

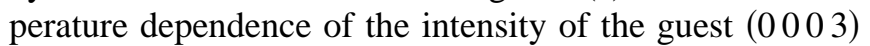
main reflection. In the low symmetry phase, it follows a rather order parameter behavior, and appears strongly reduced (but not extinct) above the transition temperature by large amplitude motions of the alkane chains in the urea channels. Figure 4(b) compares the evolutions

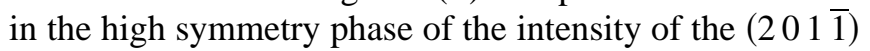
pure satellite and of the main $(2000)$ reflection. The very rapid decrease of the satellite intensity seems to indicate a significant evolution of the amplitude or form of the intermodulation, maybe correlated to the activated dynamic of the guest. The (2000) reflection is comparatively much less affected, first, because it is a common main reflection

less sensitive to intermodulation, and, second, because the possible very anisotropic Debye-Waller factor (very large amplitude translational motions of the guest were reported by inelastic incoherent neutron scattering [14]) is not efficient in the $\mathbf{a}^{*}$ direction. The knowledge of how the alkane chains are three-dimensionally ordered or disordered within the urea frame work is of fundamental importance for a better understanding of the characteristics of the interactions responsible for the intermodulation observed in $n$-nonadecane/urea.

The measured elastic neutron scattering on $n$-nonadecane urea inclusion compound has revealed the existence of satellite reflections which do not correspond to either host or guest periodicities along the channel axis. This provides, for the first time, strong evidence of an incommensurate modulation in such molecular composite systems. It is shown that a superspace description delivers a thorough understanding of the complete features of

TABLE I. Comparison of refined measured positions along $\mathbf{c}^{*}\left(l_{\text {meas }}\right)$ of different $(h k l m)$ pure satellite reflections and calculated ones $\left(l_{\text {calc }}\right)$.

\begin{tabular}{lrrrrrrrrrr}
\hline \hline$(\mathrm{l} \mathrm{m})$ & $(1 \overline{2})$ & $(\overline{1} 3)$ & $(2 \overline{4})$ & $(1 \overline{1})$ & $(\overline{1} 4)$ & $(2 \overline{3})$ & $(2 \overline{2})$ & $(11)$ & $(2 \overline{1})$ & $(12)$ \\
\hline$l_{\text {calc }}$ & 0.164 & 0.254 & 0.328 & 0.582 & 0.672 & 0.746 & 1.164 & 1.418 & 1.582 & 1.836 \\
$l_{\text {meas }}$ & 0.163 & 0.256 & 0.332 & 0.583 & 0.680 & 0.744 & 1.168 & 1.420 & 1.585 & 1.840 \\
& \pm 0.005 & \pm 0.005 & \pm 0.005 & \pm 0.005 & \pm 0.005 & \pm 0.005 & \pm 0.01 & \pm 0.01 & \pm 0.01 & \pm 0.01 \\
\hline \hline
\end{tabular}


the diffraction pattern. These experimental observations now give golden opportunities for precise analysis of this intermodulated incommensurate structure and for direct research for the reciprocal space dispersion of the previously reported sliding mode [15].

[1] T. Janssen and A. Janner, Adv. Phys. 36, 519 (1987).

[2] A. Janner and T. Janssen, Acta Crystallogr. Sect. A 36, 408 (1980).

[3] A. Meerchault, Mater. Sci. Forum 100\&101, 1-414 (1992).

[4] Y.I. Frenkel and T. Kontorova, Zh. Eksp. Teor. Fiz. 8, 1340 (1938).

[5] G. Theodorou and T. M. Rice, Phys. Rev. B 18, 2840 (1978).

[6] R. Forst, H. Jagodzinsky, H. Boysen, and F. Frey, Acta Crystallogr. Sect. B 43, 187 (1987); Acta Crystallogr. Sect. B 46, 70 (1990).
[7] K. D. M. Harris and J. M. Thomas, J. Chem. Soc. Faraday Trans. 86, 2985 (1990).

[8] K. D. M. Harris, S. P. Smart, and M. D. Hollingworth, J. Chem. Soc. Faraday Trans. 87, 3423 (1991).

[9] S. Van Smaalen and K. D. M. Harris, Proc. R. Soc. London A 452, 677 (1996).

[10] A. E. Smith, Acta Crystallogr. 5, 224 (1952).

[11] Y. Chatani, Y. Taki, and H. Tadokoro, Acta Crystallogr. Sect. B 33, 309 (1977).

[12] I. J. Shannon, K. D. M. Harris, A. J. O. Rennie, and M. B. Webster, J. Chem. Soc. Faraday Trans. 89(12), 2023 (1993).

[13] H. L. Casal, D. G. Cameron, and E. C. Kelusky, J. Chem. Phys. 80, 1407 (1984).

[14] F. Guillaume, C. Sourisseau, and A. J. Dianoux, J. Chem. Phys. 93(5), 3536 (1990).

[15] D. Smicker, S. Van Smaalen, J. L. de Boer, C. Haas, and K. D. M. Harris, Phys. Rev. Lett. 74, 734 (1995). 